\title{
Diversidade genética em seleção recorrente de maracujazeiro-amarelo detectada por marcadores microssatélites
}

\author{
Ronaldo Viana dos Reis ${ }^{(1)}$, Eder Jorge de Oliveira(2), Alexandre Pio Viana(1), Telma Nair Santana Pereira(1), \\ Messias Gonzaga Pereira(1) e Marcelo Geraldo de Morais Silva(1)
}

\begin{abstract}
(1)Universidade Estadual do Norte Fluminense Darcy Ribeiro, Avenida Alberto Lamego, o 2.000, CEP 28013-600 Campos dos Goytacazes, RJ. E-mail: ronasviana@yahoo.com.br, pirapora@uenf.br, telmasp@uenf.br, messias@uenf.br, mcoro2003@yahoo.com.br ${ }^{(2)}$ Embrapa Mandioca e Fruticultura, Rua da Embrapa, s/no, Caixa Postal 007, CEP 44380-000 Cruz das Almas, BA. E-mail: eder@cnpmf.embrapa.br
\end{abstract}

Resumo - O objetivo deste trabalho foi estimar a variabilidade genética em dois ciclos de seleção recorrente do maracujazeiro-amarelo (Passiflora edulis) e avaliar o impacto da seleção nas progênies selecionadas via alterações nas frequências alélicas, detectadas com uso de marcadores microssatélites. Vinte e três pares de iniciadores microssatélites foram utilizados na genotipagem de 66 progênies de irmãos completos. Estimaram-se a frequência alélica, heterozigosidade esperada $\left(\mathrm{H}_{\mathrm{e}}\right)$ e observada $\left(\mathrm{H}_{\mathrm{o}}\right)$, conteúdo de informação polimórfica (PIC) e coeficiente de endogamia $(f)$. Foram encontrados 32 alelos nas populações, dos quais apenas dois foram perdidos durante a seleção. O número médio de alelos por locos foi de 2,46, no primeiro ciclo, e de 2,30 no segundo ciclo. As diferenças nas frequências alélicas nos dois ciclos de seleção recorrente não foram significativas. $\mathrm{A} \mathrm{H}_{\mathrm{e}}$ média no primeiro ciclo de seleção foi de 0,20 por loco, ligeiramente maior que a $\mathrm{H}_{0}(0,15)$. No segundo ciclo de seleção, o valor médio da $\mathrm{H}_{\mathrm{o}}$ foi menor que o da $\mathrm{H}_{\mathrm{e}}$, com média de 0,12 . Os valores médios de $f$ aumentaram no segundo ciclo seletivo, de 0,26 para 0,32 . A maioria dos locos apresentou valores negativos de $f$, o que sugere altos índices de heterozigosidade. O valor médio do PIC decresceu de 0,18 para 0,16 no segundo ciclo. Houve pequena perda de variabilidade e alterações nas frequências alélicas; porém, esta oscilação pode ser considerada normal quando se pratica seleção.

Termos para indexação: Passiflora edulis, melhoramento, variabilidade genética.

\section{Genetic diversity in recurrent selection of yellow passion fruit detected by microsatellites markers}

\begin{abstract}
The objective of this work was to estimate the genetic variability in two recurrent selection cycles of the yellow passion flower (Passiflora edulis), and to evaluate the impact of selection on the progenies selected via changes in allele frequency, detected by microsatellite markers. Twenty-three microsatellites were used for genotyping 66 full-siblings. Allele frequency, expected $\left(\mathrm{H}_{\mathrm{e}}\right)$ and observed $\left(\mathrm{H}_{\mathrm{o}}\right)$ heterozygosity, polymorphic information content (PIC) and inbreeding coefficient (f) were estimated. Thirty-two alleles were found in these populations, of which only two were lost during selection. The average number of alleles per locus was 2.46 in the first cycle, and 2.30 in the second. The differences in allele frequencies in the two cycles were not significant. The mean $\mathrm{H}_{\mathrm{e}}$ in the first cycle was 0.20 per locus, slightly higher than $H_{o}(0.15)$. In the second selection cycle, the mean value of $\mathrm{H}_{\mathrm{o}}$ was lower than of $\mathrm{H}_{\mathrm{e}}$, with an average of 0.12 . The mean values of $f$ increased in the second selection cycle, from 0.26 to 0.32 . Most of the loci showed negative values of $f$, which suggests high levels of heterozygosity. The mean value of PIC decreased from 0.18 to 0.16 in the second cycle. There were small losses of variability and changes in allele frequencies; however, these variations can be considered normal when selection is practiced.
\end{abstract}

Index terms: Passiflora edulis, breeding, genetic variability.

\section{Introdução}

O gênero Passiflora é amplamente distribuído pelas Américas e possui grande variabilidade genética a ser explorada nos programas de melhoramento. O interesse econômico pelo gênero relaciona-se principalmente à produtividade de frutos, com destaque para $\mathrm{o}$ maracujazeiro-amarelo (Passiflora edulis Sims), que é a espécie mais cultivada e predominante no mercado (Oliveira et al., 2008).
O Brasil, como centro de origem do maracujá, possui ampla variabilidade genética, o que propicia programas de melhoramento genético, e cuja caracterização e avaliação são ferramentas indispensáveis (Ganga et al., 2004). Mesmo com grande importância econômica e social, a maioria dos estudos relacionados à geração de informações básicas para os programas de melhoramento genético é recente (Viana et al., 2006; Gonçalves et al., 2007; Oliveira et al., 2008). 
Embora a seleção recorrente, como método de melhoramento intrapopulacional associado às ferramentas biométricas, apresente sucesso na seleção de genótipos superiores, na cultura do maracujazeiro, seu uso tem sido restrito. Teoricamente, a seleção recorrente permite o aumento gradual da frequência dos alelos favoráveis, sem reduzir a variabilidade genética da população. Entretanto, observa-se que a seleção recorrente provoca mudanças nas frequências alélicas, na distribuição da variabilidade genética e, portanto, na estrutura genética da população original.

Estudos indicam redução na variabilidade genética após alguns ciclos de seleção recorrente, geralmente, em virtude da redução no tamanho da população (Hallauer, 1971). Essa perda na variação genética ao longo dos diversos ciclos de seleção, recombinação e avaliação pode ser mensurada com as estimativas dos componentes de variância genética (Santos et al., 2005).

No caso do maracujazeiro-amarelo, por se tratar de uma espécie semiperene, as estimativas de redução da variabilidade genética com base em informações agronômicas podem requerer muito tempo e sofrer forte influência ambiental. Na busca por métodos de seleção mais eficientes, os marcadores moleculares podem conferir algumas vantagens em relação ao processo seletivo de plantas, com economia de tempo e recursos financeiros, além de garantir a existência da diversidade genética necessária para a continuidade do programa (Coque \& Gallais, 2006).

Marcadores moleculares codominantes, como os microssatélites ou "simple sequence repeats" (SSR) são importantes na verificação das mudanças nos parâmetros genéticos das populações ao longo dos ciclos de seleção, já que identificam alterações e perdas alélicas em cada loco individualmente (Oliveira et al., 2005). Esse tipo de marcador tem sido utilizado com sucesso nos estudos dos efeitos da seleção recorrente na estrutura genética das populações sob seleção (Pinto et al., 2003).

Silva et al. (2009) utilizaram a seleção recorrente no maracujazeiro-amarelo como alternativa de capitalização de ganhos genéticos, o que aumentou a eficiência do processo seletivo e potencializou sua utilização em programas de melhoramento, por permitir o ganho genético em duas (geração e teste de progênies) das três etapas de seleção recorrente. Embora essa alternativa seja eficaz no aumento da frequência alélica de características de interesse econômico, não há informação disponível sobre as mudanças na estrutura genética da população nos últimos ciclos seletivos.

O objetivo deste trabalho foi estimar a variabilidade genética em dois ciclos de seleção recorrente do maracujazeiro-amarelo e avaliar o impacto da seleção nas progênies selecionadas via alterações nas frequências alélicas, detectadas com uso de marcadores microssatélites.

\section{Material e Métodos}

Avaliaram-se 66 progênies, das quais 27 provenientes do primeiro ciclo de seleção recorrente na população UENF/MA, formada pela combinação das variedades: Maguary, Yellow Master e seleções de São Francisco do Itabapoana, nomeadas como Maracujá-Amarelo Zero $\left(\mathrm{MA}_{0}\right)$, cujos genótipos foram selecionados de 113 progênies de maracujá-amarelo do trabalho de Gonçalves (2005). As outras 39 progênies foram selecionadas por Silva et al. (2009), advindas de cruzamentos dirigidos, que envolveram 26 progênies de maracujazeiro-amarelo selecionadas previamente por Gonçalves (2005). As progênies do primeiro e segundo ciclos de seleção recorrente foram avaliadas no município de Campos dos Goytacazes, RJ, no período de junho de 2005 a dezembro de 2006, e outubro de 2007 a dezembro de 2009, respectivamente.

O DNA genômico total foi extraído de folhas dos genótipos de maracujazeiro, segundo o protocolo descrito por Doyle \& Doyle (1990).

Foram utilizados 23 iniciadores microssatélites pertencentes à série $\mathrm{PE}$, desenvolvidos por Oliveira (2006) (Tabela 1). As reações de amplificação foram realizadas conforme descrito por Oliveira (2006), com pequenas modificações ajustadas para cada mistura.

O volume das reações de amplificação foi de $20 \mu \mathrm{L}$, com 20 ng de DNA genômico; $50 \mathrm{mmol} \mathrm{L}^{-1}$ $\mathrm{KCl} ; 10$ mmol L-1 Tris-HCl (pH 8,8); 0,1\% Triton-X; 1,5 mmol L-1 $\mathrm{MgCl}_{2} ; 100 \mu \mathrm{mol} \mathrm{L}{ }^{-1}$ de cada dNTPs; $0,2 \mu \mathrm{mol} \mathrm{\textrm {L } ^ { - 1 }}$ de cada iniciador e 0,5 unidades de Taq polimerase Invitrogen (Invitrogen, Carlsbad, CA, EUA).

As amplificações foram realizadas em Termociclador Modelo PTC 100 (MJ Research, Watertown, MA, EUA). Foram utilizadas duas diferentes condições de amplificação em esquema de "touchdown", com base nos programas TD60 (um ciclo de $94^{\circ} \mathrm{C}$ por $5 \mathrm{~min}$; 
8 ciclos de $94^{\circ} \mathrm{C}$ por $40 \mathrm{~s}, 60 \pm 0,5^{\circ} \mathrm{C}$ por ciclo por $40 \mathrm{~s}$ e $72^{\circ} \mathrm{C}$ por $50 \mathrm{~s} ; 24$ ciclos de $94^{\circ} \mathrm{C}$ por $40 \mathrm{~s}, 56^{\circ} \mathrm{C}$ por $40 \mathrm{~s}, 72^{\circ} \mathrm{C}$ por $50 \mathrm{~s}$; um ciclo de $72^{\circ} \mathrm{C}$ por $5 \mathrm{~min}$ ) e TD56 (um ciclo de $94^{\circ} \mathrm{C}$ por $5 \mathrm{~min} ; 12$ ciclos de $94^{\circ} \mathrm{C}$ por $40,56 \pm 0,5^{\circ} \mathrm{C}$ por ciclo a $40 \mathrm{~s}, 72^{\circ} \mathrm{C}$ por $50 \mathrm{~s} ; 20$ ciclos de $94^{\circ} \mathrm{C}$ por $40 \mathrm{~s}, 56^{\circ} \mathrm{C}$ por $40 \mathrm{~s}, 72^{\circ} \mathrm{C}$ por $50 \mathrm{~s}$; um ciclo de $72^{\circ} \mathrm{C}$ por $5 \mathrm{~min}$ ).

Para os iniciadores PE12, PE75 e PE88 a utilização de uma temperatura de anelamento específica $\left(60^{\circ} \mathrm{C}\right)$ produziu melhores resultados (Tabela 1). O programa básico foi constituído por uma desnaturação inicial de $94^{\circ} \mathrm{C}$ por $5 \mathrm{~min} ; 30$ ciclos de $94^{\circ} \mathrm{C}$ por $40 \mathrm{~s} ; 60^{\circ} \mathrm{C}$ por $40 \mathrm{~s} ; 72^{\circ} \mathrm{C}$ por $50 \mathrm{~s}$; e uma extensão final de $5 \mathrm{~min}$ a $72^{\circ} \mathrm{C}$. Dois protocolos foram usados para eletroforese: no primeiro, locos contendo fragmentos com diferença de tamanho inferior a $10 \mathrm{bp}$ foram separados em géis de poliacrilamida desnaturante ( $6 \%$ poliacrilamida), e, em seguida, corados com nitrato de prata (Creste et al., 2001); no segundo, locos contendo fragmentos com diferenças acima de $10 \mathrm{pb}$ foram submetidos à eletroforese em gel de agarose 1000 a 3\% p/v (Invitrogen, Carlsbad, CA, EUA). Utilizou-se o "ladder" 50 pb (New England Biolabs, Inc., Beverly, MA, EUA) como padrão de peso molecular, para comparar o tamanho dos alelos dos microssatélites.

Foram estimadas as frequências alélicas, a heterozigosidade observada $\left(\mathrm{H}_{\mathrm{o}}\right)$, a heterozigosidade esperada $(\mathrm{He})$, o coeficiente médio de endogamia $(f)$ e o conteúdo médio de informação polimórfica (PIC), com o programa PowerMarker versão 3.25 (Liu \& Muse, 2005) e o índice Shannon-Wiener (H'), e o teste t para verificar alterações na diversidade das duas populações por meio do programa Genes (Cruz, 2008).

\section{Resultados e Discussão}

Dos 23 iniciadores analisados, 10 foram monomórficos e o restante polimórfico. Observaram-se 32 alelos nas populações, dos quais 30 comuns às populações $\mathrm{MA}_{0}$ e $\mathrm{MA}_{1}$ (Tabela 2).

O número de alelos por loco variou de dois a quatro, com média de 2,46 na população $\mathrm{MA}_{0}$ e de 2,31 na população $\mathrm{MA}_{1}$. Oliveira et al. (2005) encontraram até 20 alelos por loco na análise de acessos de

Tabela 1. Locos microssatélites (SSR), iniciadores, tamanho esperado do alelo em pares de bases (pb), mistura e programa de temperatura de anelamento (TA) de todos os iniciadores utilizados no estudo.

\begin{tabular}{|c|c|c|c|c|}
\hline Loco & Iniciador "forward" & Iniciador "reverse" & Alelo (pb) & $\mathrm{TA}^{(1)}$ \\
\hline PE74 & CCCTCTTATCAATAGCGTTGG & GCACGAGCACGAGTATTTATT & 215 & TD56 \\
\hline PE08 & CCGGATACCCACGCATTA & TCTAATGAGCGGAGGAAAGC & 282 & TD56 \\
\hline PE38 & GATCGGTCCTCGGTTAGAC & AGTCACACAGCATGAGAAATC & 215 & TD56 \\
\hline PE23 & CAATCCCTTGACCCATAGA & CGTCCATCCTTCTCCTTT & 206 & TD56 \\
\hline PE59 & GAACACTTCGCATGGCTAGA & TTCCGAATCAAACCGTAACT & 276 & TD56 \\
\hline PE03 & GCAGCGAGGGAAGAAAAA & TGAGACATCGTGCGTGAA & 156 & TD60 \\
\hline PE37 & CAAAAGGATAGGCCTGATGTC & TGCTTGGTCATCCACTGAAG & 232 & TD60 \\
\hline PE58 & GCAATTTCACCATCTTCTGCT & CCACGGTCATGGATGTTC & 243 & TD60 \\
\hline PE11 & GCATAAGTTGTCGGTCTTGG & CCTCGAACCTCTATCATCCA & 178 & TD60 \\
\hline PE13 & AAGCACCCCAATCGTTGA & ССССCTGCCACCTGAGTA & 172 & TD60 \\
\hline PE04 & ATGCTTTTGGAAATCCGTTT & TGCTCATGCAAAGTCACTGG & 235 & TD60 \\
\hline PE24 & TCAAACTGAACTCGTAAAGG & GTGCTGGGAGACTGATGTT & 294 & TD60 \\
\hline PE27 & TTGCTCATTGCACTCATCCT & GCAGACATTTCCTGGAGCA & 139 & TD60 \\
\hline PE41 & ATCGGGGTTCGCTTATTTG & CGTTCATCCTTTAGTGGGCTA & 220 & TD60 \\
\hline PE66 & CCATAGTCCCAACAAGCATC & GCTGTGGACCCTAACTCAGTC & 165 & TD60 \\
\hline PE90 & TCAGGAAGATTGCATGTTAGT & CTGGGTTTTGTTTATGTTGC & 245 & TD60 \\
\hline PE12 & CGTAATATTGTTTGGGCACT & ATCATGGGCGAACTCATTT & 150 & $60^{\circ} \mathrm{C}$ \\
\hline PE18 & CCGTGAACCAACCATTTCTC & TTGCAGCACAAACAAGTCAA & 220 & TD60 \\
\hline PE20 & AGGATCACCATAGAAAACCAT & GTTAGGTTGGCATTGCTCTT & 242 & TD60 \\
\hline PE35 & ATTATGCCTAAAAACCCAAA & TGATCCAGAGGTTGAGAGG & 225 & TD60 \\
\hline PE42 & GTCACTTCATTCTTCCTTTCC & TTAGCCCACTCAAACACAA & 216 & TD60 \\
\hline PE75 & CACAATCGGTGGGAAAGATA & GTAGTTTTGGGCAGTTTGC & 178 & $60^{\circ} \mathrm{C}$ \\
\hline PE88 & CTTCAGGGTCACACACATT & GTTCATCCTTTAGTGGGCT & 293 & $60^{\circ} \mathrm{C}$ \\
\hline
\end{tabular}

${ }^{(1)} \mathrm{TD} 56$ : um ciclo de $94^{\circ} \mathrm{C}$ por $5 \mathrm{~min} ; 12$ ciclos de $94^{\circ} \mathrm{C}$ por $40 \mathrm{~s}, 56 \pm 0,5^{\circ} \mathrm{C}$ por ciclo a $40 \mathrm{~s}, 72^{\circ} \mathrm{C}$ por $50 \mathrm{~s} ; 20$ ciclos de $94^{\circ} \mathrm{C}$ por $40 \mathrm{~s}, 56^{\circ} \mathrm{C}$ por $40 \mathrm{~s}, 72^{\circ} \mathrm{C}$ por $50 \mathrm{~s}$; um ciclo de $72^{\circ} \mathrm{C}$ por $5 \mathrm{~min}$. TD60: um ciclo de $94^{\circ} \mathrm{C}$ por $5 \mathrm{~min}$; oito ciclos de $94^{\circ} \mathrm{C}$ por $40 \mathrm{~s}, 60 \pm 0,5^{\circ} \mathrm{C}$ por ciclo por $40 \mathrm{~s}$ e $72^{\circ} \mathrm{C}$ por $50 \mathrm{~s} ; 24$ ciclos de $94^{\circ} \mathrm{C}$ por $40 \mathrm{~s}, 56^{\circ} \mathrm{C}$ por $40 \mathrm{~s}, 72^{\circ} \mathrm{C}$ por $50 \mathrm{~s}$; um ciclo de $72^{\circ} \mathrm{C}$ por $5 \mathrm{~min}$. Temperatura específica: $60^{\circ} \mathrm{C}$. 
maracujazeiro-amarelo. O baixo número de alelos observados neste trabalho pode estar associado à base genética estreita dos parentais, oriundos de genótipos coletados em áreas comerciais da região do Norte Fluminense. Como os agricultores geralmente utilizam sementes do próprio pomar para formação de novas lavouras, a seleção dos melhores frutos e das melhores plantas contribui para que haja forte pressão seletiva.

A seleção recorrente na população $\mathrm{MA}_{0}$ ocasionou a fixação do alelo A1 no loco PE74, e na população $\mathrm{MA}_{1}$, a perda do alelo A3 no loco PE42 (Tabela 2). Resultados semelhantes foram obtidos por Furlan et al. (2007), em que quatro alelos foram perdidos durante a seleção recorrente em Pinus caribaea Morelet var. hondurensis (Sénécl.) W.H.G. Barrett \& Golfari. Em milho, Hagdorn et al. (2003) observaram a perda de quase um alelo por loco dos progenitores nas linhagens de milho da população Iowa Stiff Stalk Synthetic e mais de um alelo na população Iowa Corn Borer Synthetic №1.

A maior pressão de seleção em populações pequenas pode resultar em problemas com o tamanho efetivo da população, o que aumenta a possibilidade da perda de alelos importantes, por causa de oscilação genética. Poucos estudos na literatura definem a adequada intensidade de seleção; porém, seleções entre 10 e $25 \%$ da população são recomendadas (Flachenecker et al., 2006). Na população de maracujazeiro-amarelo em estudo, foram selecionados $30 \%$ das melhores progênies com auxílio de índices de seleção (Silva

Tabela 2. Frequências dos alelos A1, A2, A3 e A4 dos 13 locos microssatélites polimórficos avaliados em progênies oriundas de dois ciclos de seleção recorrente de maracujazeiro-amarelo $\left(\mathrm{MA}_{0}\right.$ e $\left.\mathrm{MA}_{1}\right)$.

\begin{tabular}{|c|c|c|c|c|c|c|c|c|}
\hline \multirow[t]{2}{*}{ Loco } & \multicolumn{4}{|c|}{$\mathrm{MA}_{0}$} & \multicolumn{4}{|c|}{$\mathrm{MA}_{1}$} \\
\hline & A1 & A2 & A3 & A4 & A1 & A2 & A3 & A4 \\
\hline PE04 & 0,04 & 0,83 & 0,02 & 0,11 & 0,05 & 0,79 & 0,06 & 0,09 \\
\hline PE11 & 0,83 & 0,17 & - & - & 0,83 & 0,17 & - & - \\
\hline PE74 & 0,94 & 0,06 & - & - & 1,00 & - & - & - \\
\hline PE37 & 0,93 & 0,06 & 0,02 & - & 0,95 & 0,03 & 0,03 & - \\
\hline PE20 & 0,78 & 0,22 & - & - & 0,76 & 0,24 & - & - \\
\hline PE66 & 0,04 & 0,96 & - & - & 0,03 & 0,97 & - & - \\
\hline PE18 & 0,04 & 0,06 & 0,91 & - & 0,08 & 0,04 & 0,88 & - \\
\hline PE24 & 0,33 & 0,52 & 0,15 & - & 0,26 & 0,59 & 0,15 & - \\
\hline PE38 & 0,07 & 0,93 & - & - & 0,03 & 0,97 & - & - \\
\hline PE42 & 0,04 & 0,91 & 0,06 & - & 0,05 & 0,95 & - & - \\
\hline PE90 & 0,04 & 0,96 & - & - & 0,03 & 0,97 & - & - \\
\hline PE75 & 0,02 & 0,98 & - & - & 0,01 & 0,99 & - & - \\
\hline PE58 & 0,13 & 0,87 & - & - & 0,10 & 0,90 & - & - \\
\hline
\end{tabular}

et al., 2009). A restrição na variabilidade dessa população está mais relacionada à menor variabilidade molecular da população original do que ao rigor da seleção recorrente.

São considerados alelos raros aqueles que apresentam frequência menor que 0,05. Foram observados seis alelos raros comuns às populações $\mathrm{MA}_{0}$ e $\mathrm{MA}_{1}$ (PE04-A1, PE37-A3, PE66-A1, PE42-A11, PE90-A1 e PE75-A1). Os alelos PE04-A3 e PE18-A1 deixaram de ser raros na população $\mathrm{MA}_{1}$, em razão do aumento da sua frequência em virtude do processo seletivo. A hipótese de que esses alelos estejam ligados a genes de interesse agronômico, selecionados na geração $\mathrm{MA}_{1}$, deve ser avaliada em trabalhos futuros. Esse mesmo comportamento foi encontrado para o alelo Acp-1, que se correlaciona com produtividade (Revilla et al., 1997), e para Acp-1, Got-1, Prx-1 e Adh-1, que se correlacionam com produtividade, maturidade e outras características foliares de interesse em milho (Pollak et al., 1984). A frequência dos alelos PE37-A2, PE18-A2 e PE38-A1 diminuiu durante o processo seletivo, o que os tornou raros na população melhorada (Tabela 2). É provável que a seleção dirigida leve a modificações na variabilidade e à perda de alelos no processo, possivelmente por causa do efeito amostral dos indivíduos.

A heterozigosidade esperada $\left(\mathrm{H}_{\mathrm{e}}\right)$ na população $\mathrm{MA}_{0}$ variou de 0,04 , no loco PE75, a 0,60 no loco PE24 (Tabela 3). A heterozigosidade observada $\left(\mathrm{H}_{\mathrm{o}}\right)$ variou de 0,04, nos locos PE75 e PE37, a 0,41 no loco PE24, com média de 0,15 . Para a população $\mathrm{MA}_{1}$, a $\mathrm{H}_{\mathrm{e}}$ variou de 0 , para o loco PE74, a 0,56 no loco PE24. A fixação do alelo A1 no loco PE74 contribui para $\mathrm{H}_{\mathrm{e}}=0$ na população melhorada. $\mathrm{A}_{\mathrm{o}}$ foi menor que a $\mathrm{H}_{\mathrm{e}}$ na população $\mathrm{MA}_{1}$, com média de 0,12 ; os locos PE18 e PE24 apresentaram as maiores estimativas, 0,23 e 0,41 , respectivamente. Estimativas médias de $\mathrm{H}_{\mathrm{o}}$ e $\mathrm{H}_{\mathrm{e}}, 0,52$ e 0,54 , respectivamente, foram obtidas por meio da análise de germoplasma não melhorado de maracujazeiro-amarelo com marcadores microssatélites (Oliveira et al., 2005).

Foi detectada pequena redução nas estimativas da $\mathrm{H}_{\mathrm{e}}$ média nas populações $\mathrm{MA}_{0}$ e $\mathrm{MA}_{1}$ (Tabela 3 ). $\mathrm{O}$ teste $\mathrm{t}$ revelou que as alterações na diversidade das duas populações não foram significativas. Essa redução corrobora observações de Holthaus \& 
Lamkey (1995) e Revilla et al. (1997), após a análise de 11 e 3 ciclos de seleção recorrente em milho.

A manutenção da diversidade genética média, ao longo das gerações de seleção recorrente, permite ganhos nas gerações seguintes para as principais características sob seleção, tais como número médio de frutos por planta, peso médio de frutos, comprimento médio de frutos, largura média de frutos e espessura média de casca (Silva et al., 2009).

Os índices de coeficiente de endogamia $(f)$ foram negativos para os locos PE74, PE66, PE18, PE38, PE42, PE90, PE75 e PE58, o que sugere alta heterosigosidade (Tabela 3). Os valores negativos se devem à ocorrência de níveis maiores de $\mathrm{H}_{\mathrm{o}}$ em relação à $\mathrm{H}_{\mathrm{e}}$, para cada loco, em cada população. Valores positivos de $f$ foram observados nos locos PE04, PE11, PE37, PE20 e PE24, o que indica a existência de endogamia. $\mathrm{O} f$ médio da população $\mathrm{MA}_{1}$ foi de 0,32 ; foram observados altos índices de endogamia nos locos PE11, PE20 e PE74.

A distribuição nos valores de $f$ para os diferentes locos de microssatélites, alguns positivos e outros negativos nas duas populações, mostra que a seleção afeta a constituição genotípica dos indivíduos de maneira direcionada. Mesmo havendo indicação de endogamia em cinco locos de microssatélites, não foi observada depressão por endogamia nas progênies de maracujazeiro-amarelo para as principais características agronômicas analisadas na seleção recorrente, como observado por outros autores (Holthaus \& Lamkey, 1995).
A análise do coeficiente de endogamia possibilita mensurar a deficiência ou excesso de heterozigotos nas populações. A redução dos indivíduos de uma população causa o aumento das taxas de endogamia aleatória e maiores efeitos da deriva genética, o que leva a perdas de alelos importantes. Ao realizar estudo de diversidade genética em dez populações de Baccharis trimera (Less.) DC., com o uso de marcadores microssatélites, Auler (2004) observou valores de $f$ positivos, ainda que baixos, na maioria das populações analisadas.

Falconer \& Mackay (1996) demonstraram que o coeficiente de endogamia em uma dada geração é função, além de outros fatores, do tamanho efetivo populacional. A deriva genética pode acarretar perda de alelos favoráveis ou fixação dos alelos desfavoráveis, e pode haver redução acentuada da variabilidade genética, o que pode comprometer os ganhos genéticos (Hallauer et al., 1988). Portanto, a intensidade de seleção a ser aplicada é uma decisão importante, já que, se for muito elevada, pode ocorrer deriva genética por causa do tamanho efetivo reduzido das populações geradas pela recombinação das progênies selecionadas.

O PIC dos marcadores variou de 0,07 a 0,52 no loco PE24, com média de 0,18 na população $\mathrm{MA}_{0}$ (Tabela 3). Na população $\mathrm{MA}_{1}$, as estimativas do PIC variaram de 0 a 0,50 , com média de 0,16 . Ao avaliar uma amostra de 43 plantas de 12 diferentes acessos de $P$. edulis, Oliveira et al. (2005) obtiveram valores de PIC que variaram de 0 a 0,81 . Essa diferença pode

Tabela 3. Heterozigosidade esperada $\left(\mathrm{H}_{\mathrm{e}}\right)$, heterozigosidade observada $\left(\mathrm{H}_{\mathrm{o}}\right)$, coeficiente de endogamia $(f)$, conteúdo de informação de polimorfismo (PIC) e índice de Shannon-Wiener (H') de progênies oriundas dos dois ciclos de seleção recorrente de maracujazeiro-amarelo $\left(\mathrm{MA}_{0}\right.$ e $\left.\mathrm{MA}_{1}\right)$.

\begin{tabular}{|c|c|c|c|c|c|c|c|c|c|c|}
\hline \multirow[t]{2}{*}{ Loco } & \multicolumn{5}{|c|}{$\mathrm{MA}_{0}$} & \multicolumn{5}{|c|}{$\mathrm{MA}_{1}$} \\
\hline & $\mathrm{H}_{\mathrm{e}}$ & $\mathrm{H}_{\mathrm{o}}$ & $f$ & PIC & $\mathrm{H}^{\prime}$ & $\mathrm{H}_{\mathrm{e}}$ & Ho & $f$ & PIC & $\mathrm{H}^{\prime}$ \\
\hline PE04 & 0,29 & 0,26 & 0,11 & 0,27 & 0,83 & 0,35 & 0,21 & 0,42 & 0,33 & 0,96 \\
\hline PE11 & 0,28 & 0,11 & 0,60 & 0,24 & 0,68 & 0,28 & 0,13 & 0,54 & 0,24 & 0,70 \\
\hline PE74 & 0,10 & 0,11 & $-0,06$ & 0,10 & 0,35 & 0,00 & 0,00 & 1,00 & 0,00 & 0,00 \\
\hline PE37 & 0,14 & 0,04 & 0,73 & 0,13 & 0,32 & 0,10 & 0,05 & 0,48 & 0,10 & 0,20 \\
\hline PE20 & 0,35 & 0,07 & 0,79 & 0,29 & 0,73 & 0,37 & 0,08 & 0,79 & 0,30 & 0,76 \\
\hline PE66 & 0,07 & 0,07 & $-0,04$ & 0,07 & 0,26 & 0,05 & 0,05 & $-0,03$ & 0,05 & 0,20 \\
\hline PE18 & 0,17 & 0,19 & $-0,12$ & 0,16 & 0,60 & 0,21 & 0,23 & $-0,10$ & 0,20 & 0,69 \\
\hline PE24 & 0,60 & 0,41 & 0,32 & 0,52 & 1,43 & 0,56 & 0,41 & 0,27 & 0,50 & 1,47 \\
\hline PE38 & 0,14 & 0,15 & $-0,08$ & 0,13 & 0,42 & 0,05 & 0,05 & $-0,03$ & 0,05 & 0,20 \\
\hline PE42 & 0,17 & 0,19 & $-0,08$ & 0,16 & 0,60 & 0,10 & 0,10 & $-0,05$ & 0,09 & 0,33 \\
\hline PE90 & 0,07 & 0,07 & $-0,04$ & 0,07 & 0,26 & 0,05 & 0,05 & $-0,03$ & 0,05 & 0,20 \\
\hline PE75 & 0,04 & 0,04 & $-0,02$ & 0,04 & 0,16 & 0,03 & 0,03 & $-0,01$ & 0,03 & 0,12 \\
\hline PE58 & 0,23 & 0,26 & $-0,15$ & 0,20 & 0,57 & 0,21 & 0,21 & $-0,11$ & 0,17 & 0,51 \\
\hline Média & 0,20 & 0,15 & 0,26 & 0,18 & 0,56 & 0,18 & 0,12 & 0,32 & 0,16 & 0,49 \\
\hline
\end{tabular}


ter sido consequência da redução da base genética nas populações $\mathrm{MA}_{0}$ e $\mathrm{MA}_{1}$.

A riqueza genética, analisada pelo índice de Shannon-Wiener $\left(\mathrm{H}^{\prime}\right)$, na população $\mathrm{MA}_{0}$ variou de 0,83 a 1,43 nos locos PE04 e PE24, respectivamente, com média de 0,56 . Na população $\mathrm{MA}_{1}$, o valor médio do H' foi ligeiramente menor do que o em $\mathrm{MA}_{0}(0,49)$, com variações semelhantes para os mesmos locos PE04 $(0,96)$ e PE24 $(1,47)$ (Tabela 3$)$.

O índice de Shannon-Wiener, proposto para mensurar a riqueza de espécies em análises populacionais, apresenta aplicações na medição da diversidade fenotípica ou genotípica dentro de populações. De acordo com esse índice, quanto mais próxima de zero, menor é a diversidade e, como as populações sofreram processos de seleção, as estimativas obtidas revelam que mesmo baixa, existe variabilidade genética suficiente para continuidade dos ciclos de seleção. Índices de diversidade semelhantes foram obtidos por Torezan et al. (2005) em Aspidosperma polyneuron Müll. Arg. para indivíduos adultos.

Os resultados da análise descritiva dos dois ciclos de seleção não mostraram variabilidade genética expressiva entre os genótipos avaliados, com base na análise dos marcadores microssatélites. Esses resultados podem ser explicados pela baixa variabilidade das populações originais, que já são variedades melhoradas. Resultados semelhantes foram obtidos por meio da análise dos marcadores "random amplified polymorphic DNA" (RAPD) (Viana et al., 2003), "inter simple sequence repeat" (ISSR) (Santos et al., 2009) e descritores morfoagronômicos (Crochemore et al., 2003). Na maioria desses trabalhos, diferentes acessos de maracujazeiro-amarelo foram utilizados e não se observou expressiva variabilidade genética, o que indica um possível estreitamento da base genética nas cultivares comerciais, sobretudo para a redução da resistência a doenças (Junqueira et al., 2003).

A baixa variabilidade molecular nas populações analisadas pode ser ainda mais reduzida em função da perda e fixação de alelos, como observado na população $\mathrm{MA}_{1}$. O monitoramento da manutenção da variabilidade genética das populações deve ser realizado nas diversas etapas da seleção recorrente, para garantir o sucesso do programa em longo prazo. Como o avanço da biotecnologia e da genômica oferecem a perspectiva de mudança gradual da seleção fenotípica para a genotípica, as possibilidades de uso dessas ferramentas para auxiliar nesse processo são inúmeras.

Alterações na variabilidade podem ocorrer em programas de seleção recorrente, em virtude do método de seleção empregado, e pode haver pequenas flutuações na variabilidade, a exemplo do trabalho de Furlan et al. (2007), em que o número médio de alelos por loco reduziu-se a cada etapa de melhoramento, de 2,35 na população base para 2,25 nas matrizes selecionadas e 1,88 na população melhorada de Pinus caribaea var. hondurensis.

\section{Conclusões}

1. As alterações no número e nas frequências alélicas da população no segundo ciclo de seleção recorrente não são significativas, e, portanto, não indicam necessidade de alteração no esquema de melhoramento adotado.

2. Embora o coeficiente de endogamia tenha aumentado na população $\mathrm{MA}_{1}$, observa-se elevada heterozigosidadenos diferentes locos de microssatélites, passível de exploração na recombinação das melhores progênies para capitalização de ganhos genéticos.

3. A população $\mathrm{MA}_{1}$ ainda possui variabilidade genética intrapopulacional para garantir a continuidade do programa de seleção recorrente.

\section{Referências}

AULER, N.M.F. Distribuição da variabilidade genética em populações naturais de Baccharis trimera (Less) DC. (carqueja) no sul do Brasil. 2004. 108p. Tese (Doutorado) - Universidade Federal de Santa Maria, Santa Maria.

COQUE, M.; GALLAIS, A. Genomic regions involved in response to grain yield selection at high and low nitrogen fertilization in maize. Theoretical and Applied Genetics, v.112, p.1205-1220, 2006.

CRESTE, S.; TULMANN NETO, A.; FIGUEIRA, A. Detection of single sequence repeat polymorphisms in denaturing polyacrylamide sequencing gels by silver staining. Plant Molecular Biology Reporter, v.19, p.299-306, 2001.

CROCHEMORE, M.L.; MOLINARI, H.B.; STENZEL, N.M.C. Caracterização agromorfológica do maracujazeiro (Passiflora spp.). Revista Brasileira de Fruticultura, v.25, p.5-10, 2003.

CRUZ, C.D. Programa Genes: diversidade genética. Viçosa: UFV, 2008. 278p.

DOYLE, J.J.; DOYLE, J.L. Isolation of plant DNA from fresh tissue. Focus, v.12, p.13-15, 1990.

FALCONER, D.S.; MACKAY, T.F. Introduction to quantitative genetics. $4^{\text {th }}$ ed. Harlow: Longman Scientific, 1996. 464p. 
FLACHENECKER, C.; FRISCH, M.; FALKE, K.C.; MELCHINGER, A.E. Trends in population parameters and best linear unbiased prediction of progeny performance in a European $\mathrm{F}_{2}$ maize population under modified recurrent full-sib selection. Theoretical and Applied Genetics, v.112, p.483-491, 2006.

FURLAN, R. de A.; MORI, E.S.; TAMBARUSSI, E.V.; MORAES, C.B. de; JESUS, F.A. de; ZIMBACK, L. Estrutura genética de populações de melhoramento de Pinus caribaea var. hondurensis por meio de marcadores microssatélites. Bragantia, v.66, p.553-563, 2007.

GANGA, R.M.D.; RUGGIERO, C.; LEMOS, E.G. de M.; GRILI, G.V.G.; GONÇALVES, M.M.; CHADAS, E.A.; WICKERT, E. Diversidade genética em maracujazeiro-amarelo utilizando marcadores moleculares fAFLP. Revista Brasileira de Fruticultura, v.26, p.494-498, 2004.

GONÇALVES, G.M. Estimativas de parâmetros genéticos em características produtivas de maracujazeiro amarelo (Passiflora edulis f. flavicarpa), baseado no delineamento I. 2005. 87p. Dissertação (Mestrado) - Universidade Estadual do Norte Fluminense Darcy Ribeiro, Campos dos Goytacazes.

GONÇALVES, G.M.; VIANA, A.P.; BEZERRA NETO, F.V.; PEREIRA, M.G.; PEREIRA, T.N.S. Seleção e herdabilidade na predição de ganhos genéticos em maracujá-amarelo. Pesquisa Agropecuária Brasileira, v.42, p.193-198, 2007.

HAGDORN, S.; LAMKEY, K.R.; FRISCH, M.; GUIMARÃES, P.E.O; MELCHINGER, A.E. Molecular genetic diversity among progenitors and derived elite lines of BSSS and BSCB1 maize populations. Crop Science, v.43, p.474-482, 2003.

HALLAUER, A.R. Changes in genetic variance for seven plant and ear traits after four cycles of reciprocal recurrent selection for yield in maize. Iowa State Journal Science, v.45, p.575-593, 1971.

HALlAUER, A.R.; RUSSELL, W.A.; LAMKEY, K.R. Corn breeding. In: SPRAGUE, G.F.; DUDLEY, J.W. (Ed.). Corn and corn improvement. $3^{\text {rd }}$ ed. Madison: American Society of Agronomy, 1988. p.463-564.

HOLTHAUS, J.F.; LAMKEY, K.R. Population means and genetic variances in selected and unselected Iowa Stiff Stalk Synthetic maize populations. Crop Science, v.35, p.1581-1589, 1995.

JUNQUEIRA, N.T.V.; ANJOS, J.R.N. dos; SILVA, A.P. de O.; CHAVE, R. da C.; GOMES, A.C. Reação às doenças e produtividade de onze cultivares de maracujá-azedo cultivadas sem agrotóxicos. Pesquisa Agropecuária Brasileira, v.38, p.1005-1010, 2003.

LIU, K.; MUSE, S.V. PowerMarker: an integrated analysis environment for genetic marker analysis. Bioinformatics, v.21, p.2128-2129, 2005.

OLIVEIRA, E.J. de. Desenvolvimento e uso de marcadores microssatélites para construção e integração de mapas genéticos de maracujá-amarelo (Passiflora edulis Sims f. flavicarpa Deg.). 2006. 152p. Tese (Doutorado) - Escola Superior de Agricultura Luiz de Queiroz, Piracicaba.
OLIVEIRA, E.J. de; PÁDUA, J.G.; ZUCCHI, M.I.; CAMARGO, L.E.A.; FUNGARO, M.H.P.; VIEIRA, M.L.C. Development and characterization of microsatellite markers from the yellow passion fruit (Passiflora edulis f. flavicarpa). Molecular Ecology Notes, v.5, p.331-333, 2005.

OLIVEIRA,E.J.de; SANTOS,V.daS.;LIMA,D.S.de;MACHADO, M.D.; LUCENA, R.S.; MOTTA, T.B.N.; CASTELLEN, M. da S. Seleção em progênies de maracujazeiro-amarelo com base em índices multivariados. Pesquisa Agropecuária Brasileira, v.43, p.1543-1549, 2008.

PINTO, L.R.; VIEIRA, M.L.C.; SOUZA JUNIOR, C.L. de; SOUZA, A.P. Reciprocal recurrent selection effects on the genetic structure of tropical maize populations assessed at microsatellite loci. Genetics and Molecular Biology, v.26, p.355-364, 2003.

POLLAK, L.M.; GARDNER, C.O.; PARKHURST, A.M. Relationships between enzyme marker loci and morphological traits in two mass-selected maize populations. Crop Science, v.24, p.1174-1179, 1984.

REVILLA, P.; VALES, M.I.; MALVAR, R.A.; ORDÁS, A. Allozyme frequencies, heterozygosity and genetic distances following S1 recurrent selection in two synthetic maize populations. Theoretical and Applied Genetics, v.95, p.1057-1061, 1997.

SANTOS, L.F. dos; OLIVEIRA, E.J. de; COSTA, J.L. Variabilidade genética de acessos de maracujazeiro com o uso de marcadores ISSR. In: CONGRESSO BRASILEIRO DE MELHORAMENTO DE PLANTAS, 5., 2009, Guarapari. Anais. Vitória: Incaper, 2009.

SANTOS, M.F.; MORO, G.V.; AGUIAR, A.M.; SOUZA JUNIOR, C.L. de. Responses to reciprocal recurrent selection and changes in genetic variability in IG-1 and IG-2 maize populations. Genetics and Molecular Biology, v.28, p.781-788, 2005.

SILVA, M.G. de M.; VIANA, A.P.; GONÇALVES, G.M.; AMARAL JÚNIOR, A.T. do; PEREIRA, M.G. Seleção recorrente intrapopulacional no maracujazeiro amarelo: alternativa de capitalização de ganhos genéticos. Ciência e Agrotecnologia, v.33, p.170-176, 2009.

TOREZAN, J.M.D.; SOUZA, R.F. de; RUAS, P.M.; RUAS, C.F.; CAMARGO, E.H.; VANZELA, A.L.L. Genetic variability of pre and post-fragmentation cohorts of Aspidosperma polyneuron Muell. Arg. (Apocynaceae). Brazilian Archives of Biology and Technology, v.48, p.171-180, 2005.

VIANA, A.P.; PEREIRA, T.N.S.; PEREIRA, M.G.; SOUZA, M.M. de; MALDONADO, J.F.M.; AMARAL JÚNIOR, A.T. do. Diversidade genética entre genótipos comerciais de maracujazeiro amarelo (Passiflora edulis f. flavicarpa) e entre espécies de passifloras nativas determinada por marcadores RAPD. Revista Brasileira de Fruticultura, v.25, p.489-493, 2003.

VIANA, A.P.; PEREIRA, T.N.S.; PEREIRA, M.G.; SOUZA, M.M. de; MALDONADO, J.F.M.; AMARAL JÚNIOR, A.T. do. Genetic diversity in yellow passion fruit populations. Crop Breeding and Applied Biotechnology, v.6, p.87-94, 2006.

Recebido em 6 de outubro de 2010 e aprovado em 6 de dezembro de 2010 